\title{
Determination of adequate positive end-expiratory pressure level required for carbon dioxide homeostasis in an animal model of infant laparoscopy
}

\author{
Jacob Karlsson ${ }^{1,2}$ (D) | Gergely H. Fodor ${ }^{3}$ (D) | Andre dos Santos Rocha ${ }^{3}$ \\ Na Lin ${ }^{3}$ | Walid Habre ${ }^{3,4}$ (D) \\ Mats Wallin ${ }^{1,5}$ \\ Magnus Hallbäck $^{5}$ | Ferenc Peták 6 \\ Per-Arne Lönnqvist ${ }^{1,2}$ (D)
}

\begin{abstract}
${ }^{1}$ Anestesi-ochIntensivvårdsavdelningen, Department of Physiology and Pharmacology (FYFA), C3, Eiksson I Lars Group - Section of Anesthesiology and Intensive Care, Karolinska Institute, Stockholm, Sweden

${ }^{2}$ Pediatric Perioperative Medicine and Intensive Care, Karolinska University Hospital Eugenivägen 23, Stockholm, Sweden

${ }^{3}$ Unit for Anaesthesiological Investigations, Department of Anesthesiology

Pharmacology Intensive Care and

Emergency Medicine, University of Geneva,

Geneva, Switzerland

${ }^{4}$ Pediatric Anesthesia Unit, Geneva Children's Hospital, Geneva, Switzerland

${ }^{5}$ Maquet Critical Care AB, Solna, Sweden

${ }^{6}$ Departmenet of Medical Physics and Informatics, University of Szeged, Szeged, Hungary
\end{abstract}

\section{Correspondence}

Jacob Karlsson, Anestesi-

ochIntensivvårdsavdelningen, C3,

Eriksson I Lars, PA Lönnqvist Group-

Section of Anesthesiology and Intensive

Care, Department of Physiology and

Pharmacology (FYFA), Karolinska Institute,

17176 Stockholm, Sweden.

Email: jacob.karlsson.1@ki.se

\section{Funding information}

This work was supported by the Karolinska Institute and partially by grants from

Maquet Critical Care AB, Solna Sweden, and the regional agreement on medical training and research (ALF) between Stockholm

County Council and the Karolinska Institute.
Background: Capnoperitoneum provides a ventilatory challenge due to reduction in end-expiratory lung volume and peritoneal carbon dioxide absorption in both children and adults. The primary aim of this controlled interventional trial was to determine the positive end-expiratory pressure (PEEP) level needed to ensure for adequate carbon dioxide clearance and preservation of carbon dioxide homeostasis in an experimental model of infant laparoscopy. The secondary aim was to evaluate potential effects on cardiac output of PEEP and abdominal pressure level variations in the same setting.

Methods: Eight chinchilla bastard rabbits were anesthetized and mechanically ventilated. Intra-abdominal pressures were randomly set to 0,6 , and $12 \mathrm{~mm} \mathrm{Hg}$ by carbon dioxide insufflation. Carbon dioxide clearance using volumetric capnography, arterial blood gas data, and cardiac output was recorded, while PEEP 3,6 , and $9 \mathrm{cmH}_{2} \mathrm{O}$ were applied in a random order.

Results: A PEEP of $9 \mathrm{cmH}_{2} \mathrm{O}$ showed restoration of carbon dioxide clearance without causing changes in arterial partial pressure of carbon dioxide and bicarbonate and with no associated deterioration in cardiac output.

Conclusion: The results promote a PEEP level of $9 \mathrm{cmH}_{2} \mathrm{O}$ in this model of infant capnoperitoneum to allow for adequate carbon dioxide removal with subsequent preservation of carbon dioxide homeostasis. The use of high PEEP was not associated with any decrease in cardiac output. 


\section{1 | INTRODUCTION}

Laparoscopic surgery is becoming increasingly common even in neonates and infants. ${ }^{1}$ The abdominal insufflation of carbon dioxide $\left(\mathrm{CO}_{2}\right)$ that is necessary for adequate surgical visualization does, however, produce a double challenge with regards to the ventilation. First, the patient is subjected to a peritoneal $\mathrm{CO}_{2}$ absorption that will require an increase in $\mathrm{CO}_{2}$ excretion by the lungs to preserve normocapnea. ${ }^{2,3}$ Second, the increase in intra-abdominal pressure (IAP) will cause an upward displacement of the diaphragm that will reduce end-expiratory lung volume, which in turn will negatively influence ventilation and make adequate $\mathrm{CO}_{2}$ removal more difficult. ${ }^{4}$ In addition to this, maintaining stable $\mathrm{CO}_{2}$ levels is particularly important in neonates and infants, were the $\mathrm{CO}_{2}$ absorption seen during capnoperitoneum has been shown to proportionally increase with smaller age and size, ${ }^{2}$ and fluctuations in $\mathrm{PaCO}_{2}$ is a main factor in the regulation of cerebral blood flow and thus a key component in preventing of neurological injury. ${ }^{5-7}$

An increased respiratory rate and/or an increased driving pressure, resulting in larger tidal volumes and minute ventilation, are the most frequently used option to increase ventilatory $\mathrm{CO}_{2}$ removal in the setting of capnoperitoneum. ${ }^{2,5}$ However, these actions are relatively poor in preserving lung volume. ${ }^{6,7}$ A potentially more effective measure to preserve lung volume is the application of positive end-expiratory pressure (PEEP) and, thus, to apply a correct PEEP during laparoscopic surgery in children can be hypothesized as being a potentially more suitable action in this context. However, it is currently not known which PEEP level may be the most appropriate in this setting. Available recommendations regarding PEEP levels are few and variable but PEEP levels of approximately $5 \mathrm{cmH}_{2} \mathrm{O}$ have been described. ${ }^{8}$ Furthermore, using excessive PEEP may cause unwanted reductions in cardiac output, by reducing venous return, and thereby interfere with hemodynamic stability and adequate gas exchange.

The primary aim of this experimental study was therefore to characterize the PEEP level needed to assure for adequate $\mathrm{CO}_{2}$ clearance $\left(\mathrm{VCO}_{2}\right)$ and preservation of arterial $\mathrm{CO}_{2}$ partial pressure $\left(\mathrm{PaCO}_{2}\right)$, in a pediatric model mimicking laparoscopic surgery. A secondary aim was to estimate cardiac output (CO), by transpulmonary thermodilution, to monitor any potential repercussions in $\mathrm{CO}$ of the increased PEEP and intra-abdominal pressure levels.

\section{2 | METHODS}

\section{1 | Animal preparation}

The study was performed at the Unit for Anaesthesiological Investigations, Department of Anesthesiology, Pharmacology and Intensive Care, University of Geneva, Geneva, Switzerland.

The experimental protocol was approved by the institutional ethics committee (registration number GE/4/17) for experimental research of the University of Geneva and animal welfare committee of

\section{Editorial Comment}

The use of laparoscopic techniques is increasing in pediatric patients. This experimental study, in a rabbit laparoscopy model, shows that a PEEP of $9 \mathrm{~cm} \mathrm{H}_{2} \mathrm{O}$ is optimal to counteract negative effects of abdominal $\mathrm{CO}_{2}$ insufflation.

the Canton of Geneva, Switzerland (Chairperson Marjolaine Philit), February 2, 2017. The rabbit model was chosen since the weight span and lung volumes of the animals are within the range of normal human neonates and small infants with mature lungs. The use of this model in the context of mechanical ventilation has previously been reported by our research group. 9,10

Eight adult chinchilla rabbits (median weight of $3.7 \mathrm{~kg}$, range 3.6-3.9 kg), purchased from the animal farm of the University of Geneva, received pre-medication with intramuscular injection of xylazine $\left(3 \mathrm{mg} \mathrm{kg}^{-1}\right)$ and ketamine $\left(15 \mathrm{mg} \mathrm{kg}^{-1}\right)$. Anesthesia was then induced by iv injection of propofol $\left(2 \mathrm{mg} \mathrm{kg}^{-1}\right)$ via an ear vein. The animals were subsequently tracheostomized and an endotracheal tube ( $4 \mathrm{~mm}$ i.d., Porte ${ }^{\circledR}$; Smiths Medical) was inserted for airway management. The jugular vein and carotid artery were cannulated for pressure measurements and blood sampling. The animals were mechanically ventilated in volume-control mode (tidal volume $7 \mathrm{~mL}$ / $\mathrm{kg}$ ) using an inspired oxygen fraction of 0.4 , and the respiratory rate was adjusted to maintain end-tidal normocapnia (5.5-6.0 kPa). Anesthesia was maintained with a continuous intravenous infusion of propofol (10 mg kg-1 $\left.\mathrm{h}^{-1}\right)$ and fentanyl $\left(50 \mu \mathrm{g} \mathrm{kg}^{-1} \mathrm{~h}^{-1}\right)$ via the ear vein. All animals were given a continuous crystalloid infusion (Ringer-acetate) for volume replacement $\left(4 \mathrm{~mL} \mathrm{~kg}^{-1} \mathrm{~h}^{-1}\right)$, and atracurium (0.5-1.0 mg kg-1 $\mathrm{h}^{-1}$ ) was administered for muscle relaxation after confirming an adequate anesthetic and analgesic depth. An intra-abdominal $\mathrm{CO}_{2}$ insufflation device (Electronic Endoflator; Karl Storz) was placed in the abdominal cavity through a small airtight incision for regulation of IAP. Airway pressure, heart rate, and rectal temperature were measured and stored on a computer at a sampling rate of $1 \mathrm{kHz}$ via an analog/digital interface converter ( $A D$ Instruments, PowerLab model 8/35 and LabChart 7).

\section{2 | Volumetric capnography and arterial blood gases}

Carotid arterial blood gas samples were taken for measurement of $\mathrm{PaCO}_{2}$ and $\mathrm{HCO}_{3}{ }^{-}$using a blood gas analyzer (Abbott i-STAT 1 Handheld Blood Gas Analyzer).

$\mathrm{VCO}_{2}$ was estimated using volumetric capnography with data from standard measurements of end-tidal $\mathrm{CO}_{2}$ concentration with a mainstream infrared $\mathrm{CO}_{2}$ sensor (Capnostat-3, Respironics Inc) as previously described. ${ }^{11,12}$ Mean $\mathrm{VCO}_{2}$ values recorded over 1 minute were used for further statistical analysis (on average $30 \mathrm{VCO}_{2}$ values). 


\section{3 | Assessment of Cardiac output using transpulmonary thermodilution}

Cardiac output (CO) was monitored by using a transpulmonary thermodilution technique (PiCCO; PULSION Medical Systems, Feldkirchen, Germany). A 3-ml thermal indicator bolus $\left(<8^{\circ} \mathrm{C}\right)$ was injected in the right atrium via the central venous catheter for each measurement. ${ }^{13}$ Due to the large number of measurements in each subject, single dilutions rather than average of triplets were used.

\subsection{Study protocol}

The rabbits were allowed a 15 minutes stabilization period before starting the study protocol. To standardize lung volume, a recruitment maneuver with PEEP $3 \mathrm{cmH}_{2} \mathrm{O}$ and $14 \mathrm{~mL} / \mathrm{kg}$ tidal volume was performed while applying two consecutive periods of 10 seconds inspiratory hold. ${ }^{10}$ This recruitment procedure was performed after surgical preparation and prior to each established PEEP level.

Figure 1 depicts the order of the experimental protocol. Baseline measurements were first performed at an IAP of $0 \mathrm{~mm} \mathrm{Hg}$ and a PEEP of $3 \mathrm{cmH}_{2} \mathrm{O}$. After this, IAP was elevated to either 6 or $12 \mathrm{~mm} \mathrm{Hg}$ in random order and recordings were repeated twice after returning to IAP $0 \mathrm{~mm} \mathrm{Hg}$. Another randomization was done for the PEEP level, which was either 6 or $9 \mathrm{cmH}_{2} \mathrm{O}$ and the whole procedure was repeated. The overall sequence was randomized prior to the study, whereas the sequence was not individually randomized for each animal. $\mathrm{VCO}_{2}, \mathrm{PaCO}_{2}, \mathrm{HCO}_{3}{ }^{-}$, and $\mathrm{CO}$ recordings were performed 3 minutes after the target IAP level was established. The time frame for each measurement block was approximately 2 minutes.

Following completion of the protocol, the animals were killed with an overdose of iv sodium thiopental (100 mg/kg).

\section{5 | Statistical analysis}

Data were checked for normal distribution with Shapiro-Wilk K2 test. Data are presented as mean \pm standard deviation (SD).

A priori and based on previous studies, ${ }^{9,10}$ we calculated a sample size of 7 animals in order to detect significant differences in $\mathrm{VCO}_{2}$, $\mathrm{PaCO}_{2}, \mathrm{HCO}_{3}^{-}$, and $\mathrm{CO}$ for the interventions (power 80\%, alpha error 0.05)

Two-way repeated measure analysis of variation with subsequent Bonferroni multiple comparison tests was used to detect significant changes in the parameters measured by considering PEEP level and IAP as within-subject factors. $P<.05$ was considered to indicate statistical significance.

GraphPad Prism (version 7.0 for Windows; GraphPad Software) was used for all statistical calculations and Microsoft Excel for Mac 2011 version 14.5.7 for data handling (Microsoft Corp.).

\section{3 | RESULTS}

All 8 animals survived the interventions associated with the protocol. Data from one rabbit is missing for PEEP $9 \mathrm{cmH}_{2} \mathrm{O}$ due to technical sampling problems.

No significant changes in $\mathrm{VCO}_{2}$ were found between IAP 0,6 , and $12 \mathrm{~mm} \mathrm{Hg}$ at PEEP 3. When increasing IAP from 0 to 6 , a significant increase in $\mathrm{VCO}_{2}$ was observed both at PEEP 6 and $9(P<.05)$. Increasing IAP from 6 to 12 did not induce any further differences in $\mathrm{VCO}_{2}$ at any PEEP level. At PEEP 6 and $9, \mathrm{VCO}_{2}$ was significantly higher for IAP 6 and 12 compared with the same intra-abdominal pressures at PEEP 3.

No significant alteration of $\mathrm{PaCO}_{2}$ was observed when increasing IAP from 0 to 6 to 12 at PEEP 9. However, a significant increase

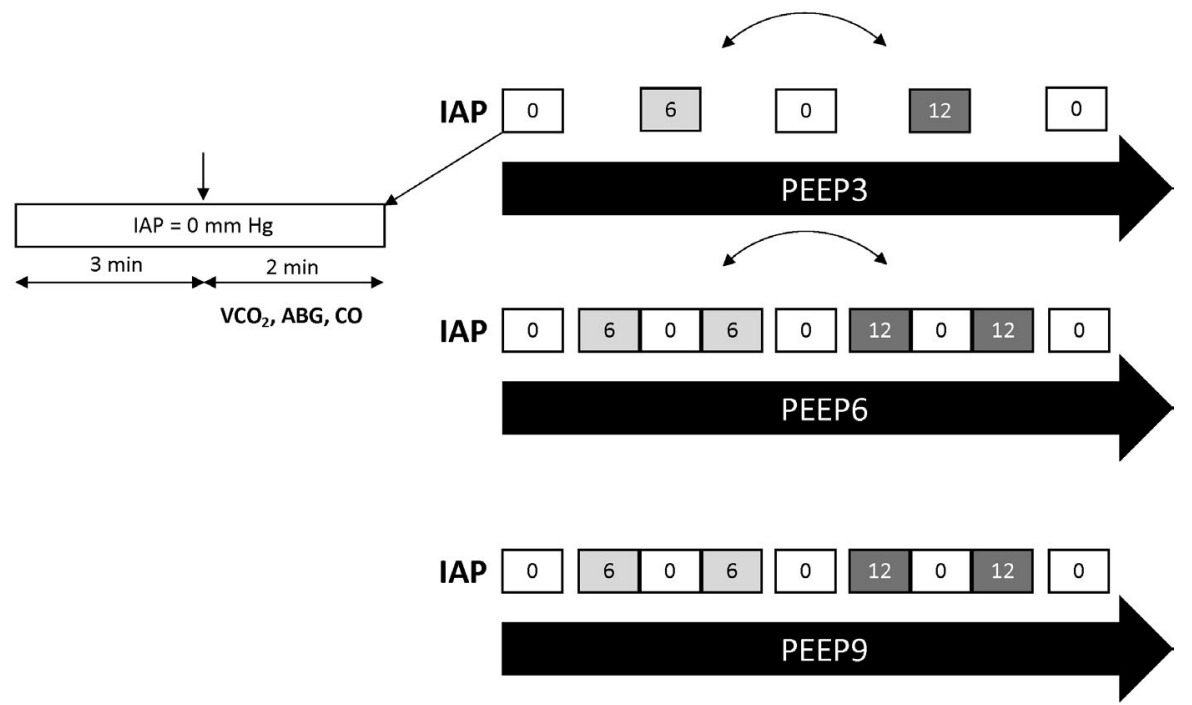

FIGURE 1 Scheme of the experimental protocol. Carbon dioxide elimination $\left(\mathrm{VCO}_{2}\right)$, arterial blood gas (ABG), and cardiac output (CO) measurements were performed at positive end-expiratory pressure (PEEP) levels of 3,6 , and $9 \mathrm{cmH}_{2} \mathrm{O}$ while intra-abdominal pressure (IAP) of 0,6 , and $12 \mathrm{mmHg}$ was randomly maintained by capnoperitoneum. After the measurements, lung volume estimations associated with another study were made 
in $\mathrm{PaCO}_{2}$ was seen for both PEEP 3 and 6 when IAP was increased from 0 to $6(P<.05)$. Increase in IAP from 6 to 12 did not cause any further significant changes in $\mathrm{PaCO}_{2}$ at PEEP 6 and 9. For baseline values, $\mathrm{PaCO}_{2}$ was slightly higher at PEEP 9 than PEEP $3(P<.05)$.

At PEEP 9, no significant changes in $\mathrm{HCO}_{3}$ - were seen between the different IAP levels. $\mathrm{HCO}_{3}$ - was at all times significantly lower at PEEP 9 when compared with PEEP 3 and 6.

No significant changes in CO were seen for PEEP 3 in response to increased IAP. For PEEP 6, CO was significantly higher at IAP6 than IAP 0. A similar difference in CO was seen between IAP 0 and 6 for PEEP 9 and also between IAP 0 and 12 for PEEP 9. At PEEP 6 and 9 , CO was significantly higher than PEEP 3 for IAP 6. For PEEP 9, CO was significantly higher than PEEP 3 also at IAP 12.

The changes in $\mathrm{VCO}_{2}, \mathrm{PaCO}_{2}, \mathrm{HCO}_{3}{ }^{-}$, and $\mathrm{CO}$ for each PEEP level and IAP step are shown in Figure 2. Additional blood gas data not associated with the aim of this study are presented in Appendix S1.

\section{4 | DISCUSSION}

The present study used an experimental model that mimics laparoscopic surgery in infants to investigate the effect of PEEP and various intra-abdominal pressures on $\mathrm{VCO}_{2}, \mathrm{PaCO}_{2}, \mathrm{HCO}_{3}{ }^{-}$, and $\mathrm{CO}$. The results indicate that the PEEP level needs to be adjusted to a minimum of $9 \mathrm{cmH}_{2} \mathrm{O}$ during abdominal insufflations of $\mathrm{CO}_{2}$ to allow for adequate $\mathrm{CO}_{2}$ removal and maintaining stable arterial $\mathrm{CO}_{2}$ tension without any associated increase in $\mathrm{HCO}_{3}{ }^{-}$. This effect of PEEP 9 was obtained with no subsequent impairment in $\mathrm{CO}$ when compared with PEEP 3 and 6.

As mentioned above, the use of laparoscopic techniques is steadily increasing in the pediatric population. ${ }^{1}$ Although the technique provides benefits for the patient and offers optimal conditions for the surgeon, this is partly achieved at the expense of adequate $\mathrm{CO}_{2}$ removal and thus provides the anesthesiologist with a substantial challenge with regards to choice of ventilation strategy. Various
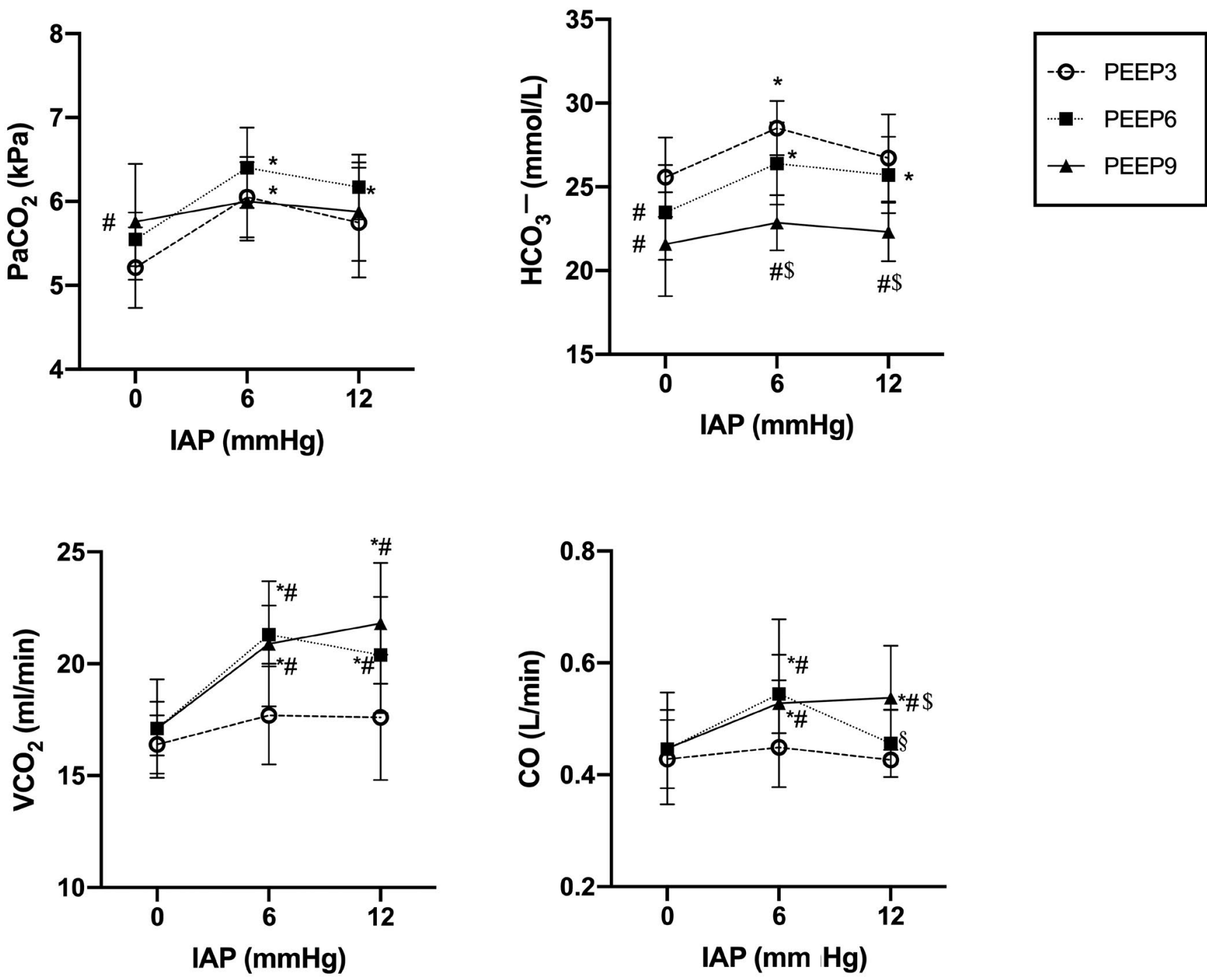

FIGURE 2 Ventilation and hemodynamic parameters. Mean \pm SD. PEEP, positive end-expiratory pressure; IAP, intra-abdominal pressure; $\mathrm{PaCO}_{2}$, arterial partial pressure of carbon dioxide; $\mathrm{HCO}_{3}{ }^{-}$, bicarbonate level; $\mathrm{VCO}_{2}$, tidal elimination rate of carbon dioxide; $\mathrm{CO}$, cardiac output by transpulmonary thermodilution. ${ }^{*} P<.05$ vs IAP0 within a PEEP, ${ }^{\S} P<.05$ vs IAP6 within a PEEP, ${ }^{\#} P<.05$ vs PEEP 3 within an IAP, $\$ P<.05$ vs PEEP 6 within an IAP 
ventilation approaches have been considered to counteract the deleterious effects of laparoscopy on lung volume. The application of appropriate PEEP level is the most suitable means to avoid reduced lung volumes, atelectasis formation, and subsequent gas exchange deterioration. ${ }^{14}$ Therefore, the results of the present study provide new and interesting information on how to ventilate neonates and small children who undergo laparoscopic surgery.

\section{1 $\mathrm{CO}_{2}$ clearance and preservation of carbon dioxide homeostasis}

A prerequisite for $\mathrm{CO}_{2}$ homeostasis during a period of increased $\mathrm{CO}_{2}$ load is that the lung is in a state that allows for increased $\mathrm{CO}_{2}$ removal. Although PEEP 3 was capable of achieving adequate arterial $\mathrm{CO}_{2}$ tension at normal IAP, it was found to be insufficient to allow for increased $\mathrm{VCO}_{2}$ in response to the $\mathrm{CO}_{2}$ load associated with IAP 6 and 12. PEEP 6 performed appropriately in this aspect at IAP 6 and appeared still partly effective at IAP 12. PEEP 9 performed well both at IAP 6 and 12 thus indicating that a PEEP level of 9 appears to be the most suitable with regards to maintaining $\mathrm{CO}_{2}$ homeostasis in this particular setting. Furthermore, even if the differences in absolute numbers of $\mathrm{PaCO}_{2}$ were relatively small between the altered PEEP levels for all IAP, this appears to be at the expense of activation of the bicarbonate buffer system. ${ }^{15}$ This is reflected by the significant increase in $\mathrm{HCO}_{3}{ }^{-}$seen at PEEP 3 and 6, whereas a stable and at all times significantly lower $\mathrm{HCO}_{3}{ }^{-}$was seen at PEEP 9.

The ability to increase $\mathrm{VCO}_{2}$ in response to external $\mathrm{CO}_{2}$ load seen at PEEP 6 and 9 is potentially mediated through decreased shunting. We suggest that this then is caused by a larger end-expiratory lung volume, with an increased part of the lung taking part in effective gas exchange. This will in turn indicate a more open and homogenous lung at the higher PEEP levels.

\subsection{Study limitations}

Since animal data cannot be immediately transposed to human babies, the use of exactly PEEP 9 cannot instantly be recommended in the clinical scenario of pediatric capnoperitoneum. However, our data indicate that an inadequate PEEP will impede $\mathrm{CO}_{2}$ elimination as $\mathrm{CO}_{2}$ is insufflated and IAP becomes raised. The inadequate $\mathrm{VCO}_{2}$ resulting from low PEEP is probably even more likely to cause further increases in $\mathrm{PaCO}_{2}$ if the insufflation period is prolonged beyond the relatively short 3 minutes used in this study. Thus, to provide a situation of unrestricted $\mathrm{CO}_{2}$ elimination by the lungs in this clinical setting, a higher PEEP than usually used appears advisable.

The assessment of $\mathrm{CO}$ in this study is associated with certain limiting issues regarding absolute values. The method should ideally be based on triplicate injection of ice-cold saline but in this study, it was based on a single injection. The rationale for this is that the small animals otherwise would have been exposed to clearly excessive volume load, both regarding animal well-being and potentially affecting CO per se. Additionally, the injected volume was reduced to only 3 milliliter instead of the customary 10 milliliters, a fact that potentially can result in a certain overestimation of $\mathrm{CO} .{ }^{16}$ However, our data are in line with what has previously been reported in this setting. ${ }^{17}$ Since the aim of assessing $\mathrm{CO}$ in this study only was to demonstrate that PEEP increases are not associated with reduced $\mathrm{CO}$, the absolute value of $\mathrm{CO}$ in this setting is of less importance. Thus, the fact that $\mathrm{CO}$ did not change during the various changes in PEEP and IAP is still indicative of stable hemodynamics throughout the various experimental manipulations.

\section{5 | CONCLUSION}

In conclusion, PEEP $9 \mathrm{~cm} \mathrm{H}_{2} \mathrm{O}$ was found to be the most effective PEEP to ensure optimal $\mathrm{CO}_{2}$ clearance without fluctuations in $\mathrm{PaCO}_{2}$ at intra-abdominal pressures of 6 and $12 \mathrm{~mm} \mathrm{Hg}$. Furthermore, PEEP 9 could be used without being associated with any decrease in cardiac output compared to lower PEEP levels.

\section{ACKNOWLEDGMENTS}

Assistance with the study: The laboratory faculty and staff of the Unit for Anaesthesiological Investigations, Dept. of Acute Medicine, University of Geneva, Geneva, Switzerland

\section{CONFLICTS OF INTEREST}

Jacob Karlsson received an unrestricted research grant from Maquet Critical Care AB. Mats Wallin and Magnus Hallbäck are employed by Maquet Critical Care AB. The other authors declare no conflicts of interest.

\section{AUTHORS' CONTRIBUTIONS}

Study design, data collection, and analysis: J.K, G.F, A.R, N.L, W.H, M.W, F.P, and PA.L. Manuscript writing and critical revision of manuscript: J.K, G.F, A.R, W.H, M.W, M.H, F.P, and PA.L.

\section{ORCID}

Jacob Karlsson (iD https://orcid.org/0000-0003-2277-0092

Gergely H. Fodor (iD https://orcid.org/0000-0002-4736-4966

Andre dos Santos Rocha iD https://orcid.org/0000-0001-6038-8500

Walid Habre iD https://orcid.org/0000-0002-6521-5091

Mats Wallin (iD https://orcid.org/0000-0003-1492-0089

Ferenc Peták iD https://orcid.org/0000-0001-6249-9327

Per-Arne Lönnqvist iD https://orcid.org/0000-0002-8586-1429

\section{REFERENCES}

1. Chan IH, Tam PK. Laparoscopic inguinal hernia repair in infants and children: state-of-the-art technique. Eur J Pediatr Surg. 2017;27:465-471.

2. McHoney M, Corizia L, Eaton S, et al. Carbon dioxide elimination during laparoscopy in children is age dependent. J Pediatr Surg. 2003;38(1):105-110; discussion-10.

3. Pacilli M, Pierro A, Kingsley C, Curry Jl, Herod J, Eaton S. Absorption of carbon dioxide during laparoscopy in children 
measured using a novel mass spectrometric technique. Br J Anaesth. 2006;97(2):215-219.

4. Kim K, Jang DM, Park JY, Yoo H, Kim HS, Choi WJ. Changes of diaphragmatic excursion and lung compliance during major laparoscopic pelvic surgery: a prospective observational study. PLOS ONE. 2018;13(11):e0207841.

5. Truchon R. Anaesthetic considerations for laparoscopic surgery in neonates and infants: a practical review. Best Pract Res Clin Anaesthesiol. 2004;18(2):343-355.

6. Levene M. Minimising neonatal brain injury: how research in the past five years has changed my clinical practice. Arch Dis Child. 2007;92(3):261-265.

7. Pryds O, Edwards AD. Cerebral blood flow in the newborn infant. Arch Dis Child Fetal Neonatal Ed. 1996;74(1):F63-F69.

8. SurekaSK PN, Mittal V, Kapoor R, et al. Safe and optimal pneumoperitoneal pressure for transperitoneal laparoscopic renal surgery in infant less than $10 \mathrm{~kg}$, looked beyond intraoperative period: A prospective randomized study. J Pediatr Urol. 2016;12(5):281.e1-. e7.

9. Albu G, Wallin M, Hallbäck $M$, et al. Comparison of static end-expiratory and effective lung volumes for gas exchange in healthy and surfactant-depleted lungs. Anesthesiology. 2013;119:101-110.

10. Albu G, Petak F, Zand T, Hallbäck M, Wallin M, Habre W. Lung volume assessments in normal and surfactant depleted lungs: agreement between bedside techniques and $C T$ imaging. BMC Anesthesiol. 2014;14:64.

11. Suarez-Sipmann F, Bohm SH, Tusman G. Volumetric capnography: the time has come. Curr Opin Crit Care. 2014;20(3):333-339.

12. Tolnai J, Fodor GH, Babik B, et al. Volumetric but not time capnography detects ventilation/perfusion mismatch in injured rabbit lung. Front Physiol. 2018;9:1805.

13. Babik B, Balogh AL, Sudy R, Ivankovitsne-Kiss O, Fodor GH, Petak F. Levosimendan prevents bronchoconstriction and adverse respiratory tissue mechanical changes in rabbits. Am J Physiol Lung Cell Mol Physiol. 2017;313(5):L950-L956.

14. Trachsel D, Svendsen J, Erb TO, von Ungern-Sternberg BS. Effects of anaesthesia on paediatric lung function. $\mathrm{Br} J$ Anaesth. 2016;117(2):151-163.

15. Brackett NC, Cohen JJ, Schwarts WB. Carbondioxidetitrationcurveofnormalman. Effectofincreasingde greesofacutehypercapniaonacid-baseequilibrium. $N$ Engl J Med. 1965;272:6-12.

16. Garofalo NA, Teixeira-Neto FJ, Rodrigues JC, Cerejo SA, Aguiar A, Becerra-Velásquez DR. Comparison of transpulmonary thermodilution and calibrated pulse contour analysis with pulmonary artery thermodilution cardiac output measurements in anesthetized dogs. J Vet Intern Med. 2016;30(4):941-950.

17. Maarek J-M, Holschneider DP, Harimoto J, Yang J, Scremin OU, Rubinstein EH. Measurement of cardiac output with indocyanine green transcutaneous fluorescence dilution technique. Anesthesiology. 2004;100(6):1476-1483.

\section{SUPPORTING INFORMATION}

Additional supporting information may be found online in the Supporting Information section.

How to cite this article: Karlsson J, Fodor GH, dos Santos Rocha A, et al. Determination of adequate positive endexpiratory pressure level required for carbon dioxide homeostasis in an animal model of infant laparoscopy. Acta Anaesthesiol Scand. 2020;64:1114-1119. https://doi. org/10.1111/aas.13617 